\begin{tabular}{ccc}
\hline & International Journal of Engineering \& Technology, $7(2.13)(2018)$ 140-144 \\
SPC & International Journal of Engineering \& Technology \\
Website: $w w w . s c i e n c e p u b c o . c o m / i n d e x . p h p / I J E T$ & Research Paper \\
\hline
\end{tabular}

\title{
Instant cereals enriched with carboxylates
}

\author{
D. A. Shaimerdenova*, Zh. M. Chakanova, M. Zh. Sultanova, A. Yu. Borovsky P. R, \\ Shaimerdenova, Kh. A. Abdrakhmanov \\ Kazakh Scientific Research Institute of Processing Agricultural Products LLP, Astana, Kazakhstan
}

\begin{abstract}
The article presents the developed technology for obtaining cereal products of rapid cooking with increased nutritional value, enriched with micronutrients, for which wheat, rice, corn and buckwheat served as raw materials. The food and biological value of the obtained instant cereals is studied, as well as the study of the effect of micronutrients-carboxylates of food acids on technological, food and consumer indices. As a result of the research, 4 prescriptions were chosen with the highest growth of micro and microelements.
\end{abstract}

Keywords: Instant Cereals; Enrichment; Micronutrients; Carboxylates of Food Acids; Nanotechnology; Extrusion

\section{Introduction}

The main criterion of food security of any country in the world, including Kazakhstan, is the stable provision of the population with quality food products. For Kazakhstan, grain is the main agricultural raw material, and grain-based products are one of the main ones, as they are simultaneously inexpensive, and at the same time, nutritious [1], [2].

The annual grain production at the level of 15-20 million tons sig nificantly covers its own needs, leaving unclaimed significant volumes that could significantly increase the profitability of cereals. However, the traditional methods used to produce cereals have a number of significant drawbacks, the most important of which are low yield of cereals and low nutritional value. In addition, as a result of numerous operations used in traditional technologies (peeling, grinding, polishing cereals), the nutritional value of the products decreases. And, as a result, finished products in the form of cereals, semi-finished products, flakes, snacks, cereal sticks, etc., are distinguished by a poor composition of minerals that do not satisfy the daily requirement of the human body for microelements [1], [2]. At the same time, the analysis of the diet of the population of Kazakhstan shows an increased interest in instant cereals, the production of which in the country is practically non-existent, and fast food products on the market are mainly represented by products from Russia, Ukraine and Belarus.

In addition, the worldwide trends in people's nutrition show that the micronutrient deficiency is becoming the main crisis of the world's population in the 21st century [3]. According to WHO experts, iron deficiency is experienced by more than 1 billion of the world population, chromium - up to 3.0 billion, copper - up to 3.8 billion, zinc - 4.5 billion. The modern human nutrition system, globalization processes occurring in the sphere of providing the population with food, the transformation of the quality of food products into a purely economic category in the conditions of an economic crisis, create serious problems in the population's nutrition. This leads to the development of the so-called "hidden hunger", namely, a micronutrient deficiency: minerals and vitamins [4].

In this regard, there is a need to maintain the level of consumption of irreplaceable micronutrients, which forms the task of increasing the nutritional value of the diet. The most effective way of improving the population's supply of micronutrients on a national scale is supplementary food enrichment with micronutrients - the way most countries of the world go [5].

So far, the enrichment of food products with mineral substances, as a rule, was carried out with salts of inorganic acids, which, due to their low bioavailability, are absorbed in the body only in a small amount and, as a result, the goal is not achieved-elimination of the microelement deficiency in the population's nutrition [5]. In addition, the use of microelements in the form of inorganic acid salts in the food industry has such a problem as a small interval between the adequate level of consumption of certain trace elements and their toxic level [6].

The most promising way of obtaining micronutrients with guaranteed safety and bioticity is the use of methods of bio-organic chemistry for the synthesis of micronutrients, which in their structure and chemical purity are related to those synthesized in a living organism. At present, the use of microelements in the form of carboxylates of food acids and, primarily, in the form of citrates, is theoretically and practically the most justified. Coordination compounds of biomaterials are widely distributed in living nature. They are part of the enzymes, hormones, vitamins and other vital compounds. It has been experimentally proven that coordination compounds of microelements are necessary for many important biological processes; their shortcoming slows down these processes or stops them. For protein, carbohydrate and fat metabolism, molybdenum, iron, vanadium, cobalt, tungsten, boron, manganese, and zinc compounds are needed. In the synthesis of protein involved compounds of magnesium, manganese, iron, cobalt, copper, nickel, chromium. In the hematopoiesis - compounds of cobalt, copper, manganese, nickel, zinc. In the breath - iron, copper, zinc, manganese, cobalt, magnesium. Therefore, the coordination compounds of these elements have recently been extensively studied and are being used [7-9].

Thus, in order to increase the content of natural micronutrients in grain products, it became necessary to develop technology for the production of quick-cooking cereals enriched with natural and safe components for the human body, such as carboxylates of food acids. The aim of the work is to fill the micronutrient deficiency in the diet of the population of Kazakhstan, as well as prevent diseases and 
improve immunity by using enriched cereals, expand the range of cereal products of fast cooking and increase the nutritional value of micronutrients - carboxylates of food acids.

For successful realization of the set goal, the following tasks were set:

1) Analysis of provision of certain groups of Kazakhstan population with food products of increased nutritional value. Study of the diet of the main layers of the population of the Republic of Kazakhstan. Development of a scientific substantiation of enrichment of products on a grain basis for optimal provision of the human body with micronutrients: macro- and microelements;

2) Development of a technology for obtaining cereal products of quick cooking of increased nutritional value, enriched with micronutrients based on carboxylates of food acids;

3) Study of food and biological value of the obtained cereal products, as well as the study of the effect of micronutrients - carboxylates of food acids on technological, food and consumer indices.

\section{Materials and methods}

Materials of the study are raw materials for the production of cereals - wheat, buckwheat, rice, corn and semolina, as well as extruded cereals of quick cooking, micro-macronutrients.

The production of carboxylates of food acids was carried out in thisway.

Preliminarily obtained by ablation of metals, for example, by electro pulse ablation, an aqueous colloidal solution in a reactor in which metal pellets are placed as described in the patent of Ukraine for the utility model Ne 23550, IPC B22F 9/14 (2007.01). Publ 25.05.2007. Bul. > 7. The metal granules are placed in a dispersion vessel and evenly placed on the bottom of the container between the electrodes. Water is poured into the container. As the pulses of electric current pass through the chains of metal granules, the energy of the pulses is transformed into the energy of sublimation of the evaporated metal. At the contact points of the metal beads, spark discharges arise one at a time, in which an explosive dispersion of the metal takes place. In the discharge channels, the temperature reaches 10,000 degrees. The areas of the surface of metal granules in the spark discharge zones melt and explode into nanoparticles and vapors. Molten nanoparticles scatter in water, cool in it and create a colloidal solution of metal nanoparticles, nanoparticles of metal oxides and metal hydroxide nanoparticles.

A carboxylic acid is poured into the resulting colloidal solution of metal nanoparticles, metal oxide nanoparticles and metal hydroxide nanoparticles. Due to the high chemical activity of the obtained nanoparticles, the formation of metal carboxylate occurs. High chemical activity of the formed nanoparticles to carboxylic acids allowed to obtain a high value of the ratio of the mass of metal carboxylate to the mass of nanoparticles.

To speed up the process, the solution was heated and vigorously stirred.

The temperature of the colloidal solution was set at about $70{ }^{\circ} \mathrm{C}$. This greatly intensified the process of obtaining carboxylates. The process was terminated when the $\mathrm{pH}$ of the final product was 3.0 to5.0.

Due to the high chemical activity of the nanoparticles, metal carboxylates were formed. Since no other substances were included in the number of reagents, and nanoparticles were almost completely involved in the chemical reaction of the formation of carboxylic acid salts, a product of high ecological purity with a very low content of impurities was formed.

The procedure for the preparation of ultrapure carboxylates $(\mathrm{Mg}$, $\mathrm{Zn}, \mathrm{Se}, \mathrm{Co}, \mathrm{Cr}, \mathrm{Fe}$ ) is shown in the specifications TU U 24.135291116-004: 2009, TU U 15.8-35291116-008: 2009, TU U 15.8.1-35291116-014 : 2009 and the patents of Ukraine № 38391, №49048, №49049, №49050, №52531, №65655. [10-15].

In developing the prescription of micronutrient premixes based on carboxylates of food acids obtained by nanotechnology, the data of the Committee on Statistics, the Academy of Nutrition, and the 1999 Medico-Demographic Study of Kazakhstan were analyzed and studied.

Laboratory labor batches of cereal products of quick cooking enriched with micronutrients based on carboxylates of food acids were obtained. The experiments were carried out in the laboratory of LLP "Kazakh Scientific Research Institute of Processing and Food Industry", extruded cereals were prepared in 5 recipes developed jointly with the Ukrainian Scientific Research Institute of Nano biotechnology. Four types of cereals were extruded for laboratory tests: wheat, corn, rice and buckwheat. The semolina was treated with aqueous solutions of citrates in 3 recipes and dried in a dryer. Rice and buckwheat groats were crushed in an experimental crusher and sifted through a No. 2 sieve, after which $1 \mathrm{~kg}$ of cereals were taken from all 4 samples and held 25-35 min.

In the process of preparing water for laying, solutions of microelements were added to the prepared water in accordance with the developed recipes.

Extrusion was carried out on a laboratory experimental extruder. The total number of extruded samples was 20 units and 3 units of semolina with 3 recipes.

The extruded cereals were dried in a drying cabinet (DC-50), ground, sorted by size using a set of sieves with hole sizes: No. 3 a sieve hole of $\varnothing 2.5 \mathrm{~mm}$, a sieve of $\varnothing 2 \mathrm{~mm}$. The obtained experimental lots of extruded cereals were sent to the Institute of Nutrition for the determination of macro and microelements before and after extrusion. The total number of croups was 28 samples.

- In studying the safety, nutritional and biological value of extruded cereals, the following methods and standards were used:

- Determination of microbiological indicators - according to GOST 26972-86.

- The content of micro and microelements, selenium, chromium, iron, zinc, were determined in accordance with GOST 30178-96, and magnesium and iodine were determined according to P.4.1.1672-2003, ch. 2, s. II, p.3.

In the laboratory "Nano engineering methods of research" on the Analyzer "Perten DA 7200" the chemical composition of the groats was studied before and after extrusion.

When studying the influence of micronutrients - carboxylates of food acids on technological, food and consumer indices of food products, the following methods and standards were used:

GOST 26312.1 - 84 Groats. Acceptance rules and methods of sampling.

GOST 26312.2-84 Groats. Methods for determining organoleptic parameters, boiling buckwheat and oat flakes.

- the degree of swelling by the Fisher method;

- content of water-soluble substances and water-retaining capacity according to the Shokh method;

The water-absorbing capacity of cereals was determined by the weight method. The weighting method consists in determining the water absorption capacity, which is characterized by the ratio of the mass of the cereal after heat treatment in water to the weight of the initial cereal.

A portion of the $100 \mathrm{~g}$ groats is filled with hot water $\left(980^{\circ} \mathrm{C}\right)$ and held for 90 minutes, then the water is drained and the water-absorbing capacity of the cereal is determined by the formula (1),

$K=\frac{T_{s}}{T_{c}}$

where $T_{s}$ - the mass of the cereal after swelling, $g, T_{c}$ - the mass of the cereal before swelling, $g$.

\section{Results}

To carry out the tasks of analyzing the provision of certain groups of the population of Kazakhstan with food products of increased nutritional value and studying the diet of the main layers, a questionnaire was conducted on a questionnaire specially developed by us. The poll involved 193 people from 15 to 63 years old living in 
Akmola, Almaty, Karaganda, Kostanay, Zhambyl, Pavlodar regions of Kazakhstan.

According to the results of the study, 59\% of respondents indicated that they use instant cereals in their food. $34 \%$ of respondents indicated a shortage of assortment of quick-cooking cereals in the places where they were sold. 19\% of respondents indicated in their wishes that there is not enough assortment of domestic quick-cookers in the Kazakhstan market, and the available analogues do not meet the needs of consumers with a price or quality side.

Analysis of the diet showed that Kazakhstanis prefer not one particular type of cereal, but several, so $78 \%$ of respondents use rice in their food, $66 \%$ of buckwheat, $59 \%$ of oatmeal, $40 \%$ of semolina, $39 \%$ of peas, $37 \%$ cereal flakes, $34 \%$ pearl rump, $30 \%$ corn grits, $23 \%$ wheat grains, $18 \%$ barley and $3 \%$ other grains and cereals, such as red lentils, mung beans, beans, millet grains (Figure 1). All without exception, the surveyed Kazakhstanis use cereal products as food products, as well as groats products of increased nutritional value.

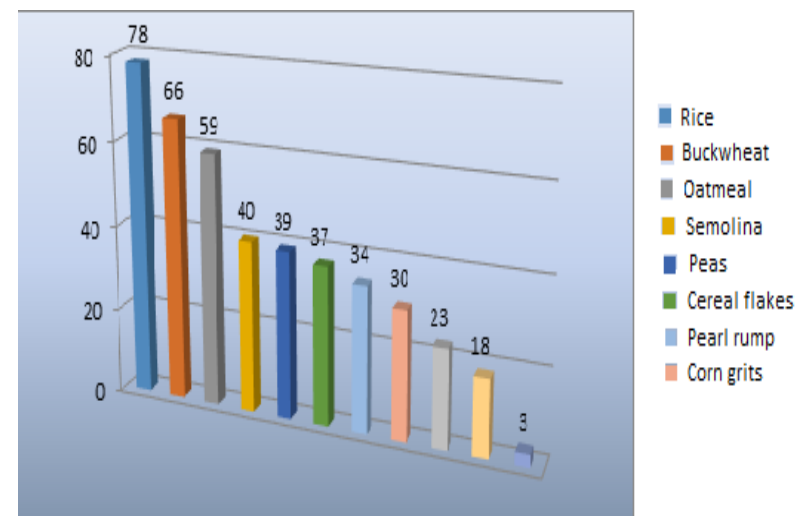

Fig. 1: Analysis of the Diet.

Preference is given to the following types of products: $61 \%$ - quickcooking cereals ("Bystrov", "AKhA", "Tsar", "Pyat zlakov", "Hercules") $57 \%$ - cereal flakes ("Nestle", "Start", "Soyuz", "Soyuzpishcheprom", "Grigorovich"), 34\% - ready-made breakfast cereals (sticks, rings, pads, etc.) ("Kuntsevo", "Nestle", "Start", "Almatinskoe", "Grigorovich"), 25\% - muesli ("Usovsko", "Danone", "AKhA", "Tsar", "Chetyre zlaka"), 21\% - instant cereals ("Vita", "Bystrov", "Kuntsevo minutka", "Uvelka", "Express"), 18\% slices ("AYAM", "Product Altaya", "Semgur", "Rokler") (Figure 2).

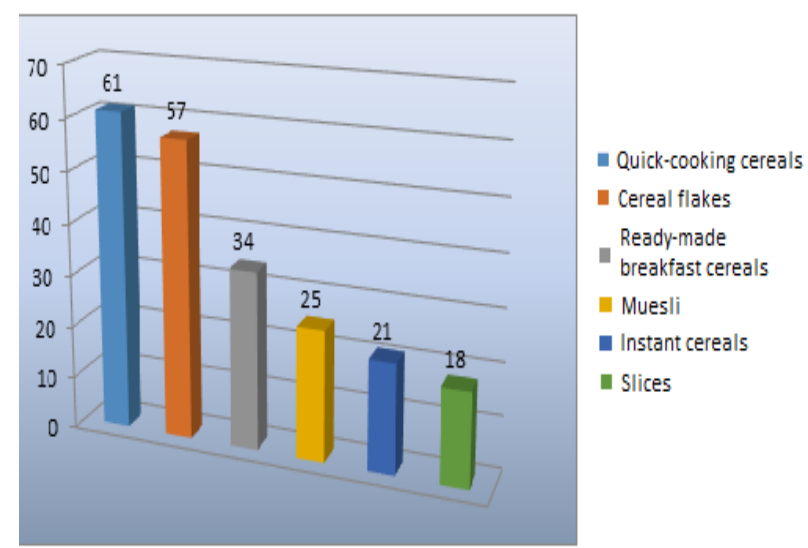

Fig. 2: Preference for Foods of Increased Nutritional Value by the Population of the Republic of Kazakhstan.

Thus, the results of the questionnaire revealed a significant need of the population of Kazakhstan for cereals with high nutritional value of quick cooking and almost complete absence of domestic production.

The analysis also showed that cereal products are characterized by insufficient content of micro- and macroelements in them to pro- vide adequate nutrition. Analysis shows that the lack of trace elements such as magnesium, selenium, iodine, zinc, chromium, can lead to a decrease in immunity, increased risk of cardiovascular and cancer.

The analysis of the ration of consumption of the population of Kazakhstan of cereal products made it possible to determine the list of micro- and macroelements, the enrichment of which must be carried out primarily for the prevention of diseases and enhance immunity. A certain list of elements for the enrichment of cereals: magnesium, zinc, iron, cobalt, selenium, chromium, for the input of which premixes have been developed.

The listed elements are introduced into premixes in the form of carboxylates (salts of organic acids) to increase their digestibility. Prescription premixes were developed on the basis of daily consumption of cereals and daily requirements for micronutrients of the human body for a particular group of the population of Kazakhstan.

Daily consumption of cereals, according to earlier studies in 2015, is 200 grams. It is expected that the required daily rate of micronutrients by $20 \%$ is covered by cereal products, the rest of the daily dose of a person will get from other foods. Based on the fact that an excess of micronutrients also dangerous as they disadvantage and leads to microelementoses, determined following daily dose trace elements for the human body: - magnesium - $400 \mathrm{mg}$.; - zinc - 15 $\mathrm{mg}$.; - iron - $10 \mathrm{mg}$.; - copper - $2 \mathrm{mg}$.; - manganese - $2 \mathrm{mg}$.; cobalt - $50 \mathrm{mkg}$; - selenium - $70 \mathrm{mkg}$.; - chrome - $50 \mathrm{mcg}$.

Prescription premixes were developed based on the need to eliminate the deficit of a specific micronutrient in a particular region of Kazakhstan.

As a result of the work, premixes were prepared for the enrichment of cereals and cereals with micronutrients based on carboxylates (salts of organic acid - citrate (citrates) for the prevention of certain diseases (Table 1)

Table 1: Prescriptions Of Premixes

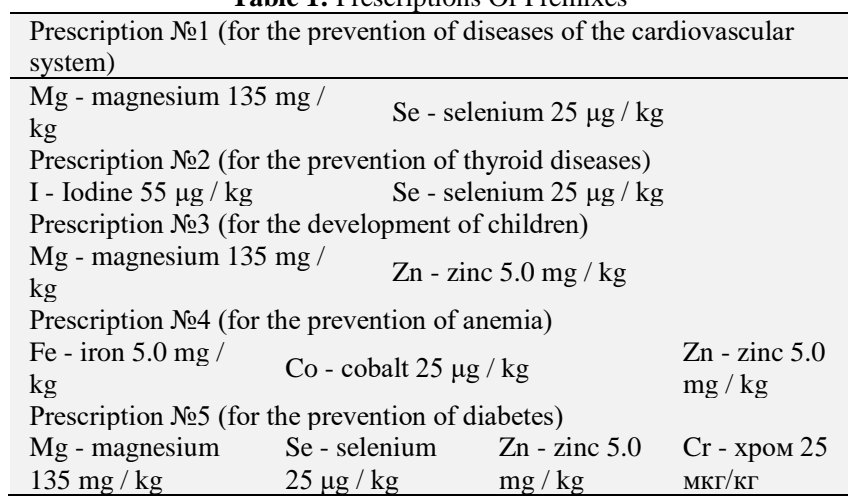

Doses are indicated per $1 \mathrm{~kg}$ of cereals and taking into account the content of pure metals.

Next, we developed a technology for obtaining cereal products of fast cooking with increased nutritional value enriched with micronutrients. The raw material for the production of cereals was wheat, rice, corn and buckwheat. The technology of obtaining cereals of fast cooking consists of a preparatory department, which consists of cleaning, peeling, sorting and crushing operations. And also from the production department, which consists of extrusion, cooling and packing operations. The technological scheme is shown in Figure 3, where the croup is cleaned of impurities by threefold separation, the separation of mineral impurities in the stone removal machines, and cleaning in triera. 


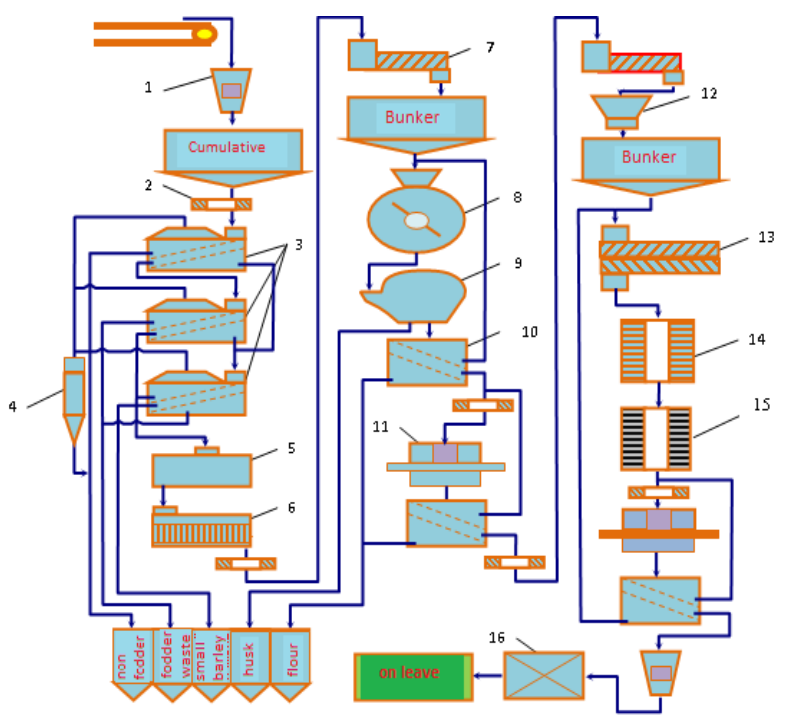

Fig. 3: Technological Scheme of Production of Cereals of Quick Cooking.

1 - Automatic scales; two - magnetic separator; 3 - separator; 4 cyclone; 5 - stone collection machine; 6 -trier; 7 - the humidifying machine; 8 - peeler; 9 - aspirator; 10 - sorting machine; 11 - crusher; 12 - batcher; 13 - extruder; 14 - dryer; 15 - cooling column; 16 packing machine.

The size of the sieve holes should be set in accordance with the type and size of the grain of the batch being processed. In order to better isolate fine grains, it is recommended that the first two separator systems install in-line sieves, the fine fraction separated by the passage to the third separator system, on which the fine grains are to be eliminated.

Peeling is carried out by four-fold sequential processing on emery grinding machines, depending on the type of raw material.

Then the products of peeling are separated from the husks and sorted by size. Sorting of products is carried out on a sorting machine.

Grinding can be carried out both on rolling machines and crushers. The product obtained after grinding is sorted to remove the flour and separate the large particles sent for re-grinding.

Further, the resulting product is subjected to moistening with the addition of trace elements in the form of citrates according to the recipe, in intensive moistening machines and sent to a hopper for lapping.

After the lagging, the product is sent for extrusion.

The resulting extrudate is subjected to short-term drying and cooling if necessary, then subjected to grinding in a hammer mill.

This technology will make it possible to obtain instant cereals with increased nutritional value due to added micronutrients based on carboxylates of food acids.

According to the developed technology and valid premix recipes, experimental batches of micronutrient-enriched cereals of quick cooking were obtained, their nutritional and biological value was studied.

The chemical, macro- and microelement composition of selected samples of extruded cereals was studied. The results of studies on the chemical, macro- and microelement composition of extruded cereals and semolina enriched with carboxylates are shown in Figures 4-6.

The protein content of the extruded cereals was at the level of the traditional cereals content of the corresponding raw material, however, in the recipe No.3 in rice and wheat the protein increased slightly. In corn groats, the protein also increased insignificantly in recipe No.2. In all 3 recipes of semolina the protein does not change and is $12.6 \%$. In the semolina, the proportion of dry matter increases in prescription number 3 .

Of the extruded cereals, the highest starch content was observed in rice groats $(98.1-101.1 \%)$.

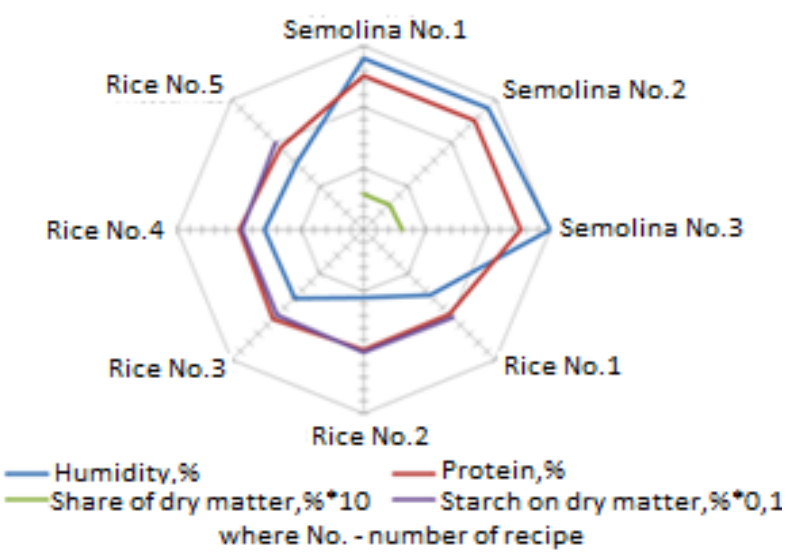

Fig. 4: Chemical Composition of Extruded Rice and Semolina Croups Enriched with Carboxylates.

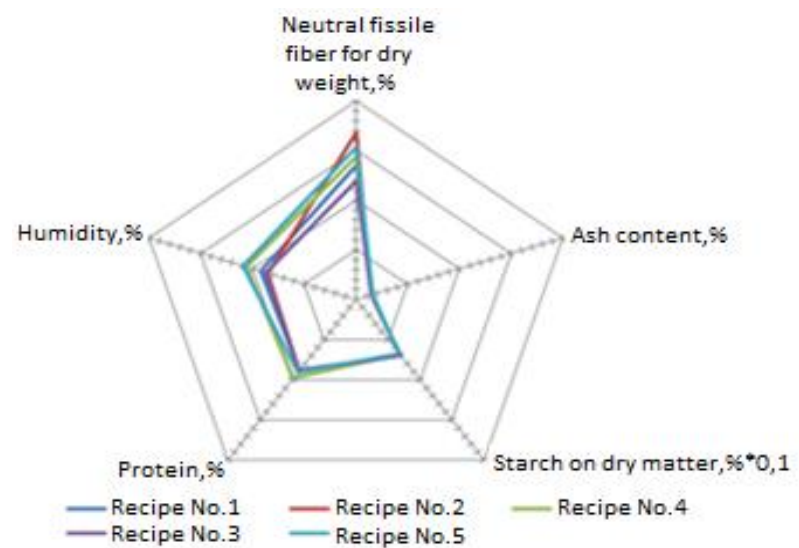

Fig. 5: Chemical Composition of Extruded Wheat Groats Enriched with Carboxylates.

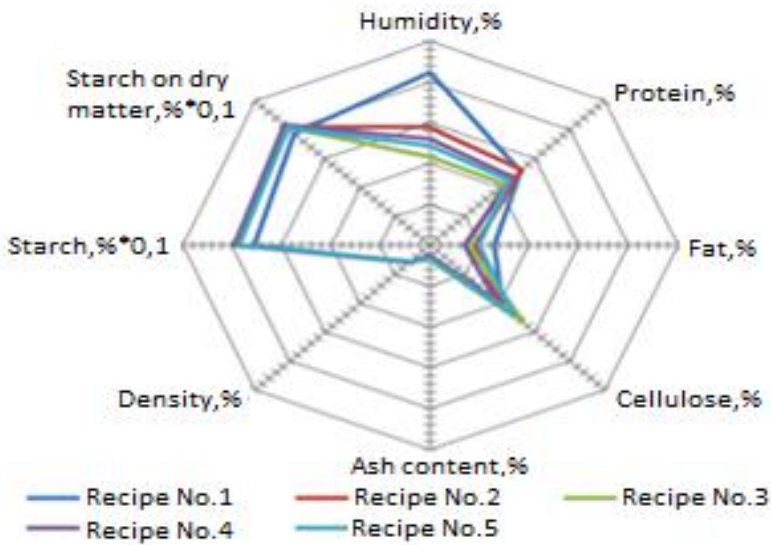

Fig. 6: Chemical Composition of Extruded Corn Greats Enriched with Carboxylates

In corn and wheat groats, the content of cellulose was determined. In corn groats the greatest amount of cellulose is observed in recipe No. $3-5,31 \%$, the smallest - in recipe No. $4-3,79 \%$. In the wheat cereal of neutrally cleaved cellulose in recipe No. 2 was $16.8 \%$, in recipe No.4-11.9\%.

The presence of a large amount of cellulose in the extruded product makes it more valuable in terms of healthy nutrition. In all 3 recipes of semolina the protein content does not change and is $12.6 \%$, as in raw materials (wheat), while the share of dry matter increased in recipe No.3. 


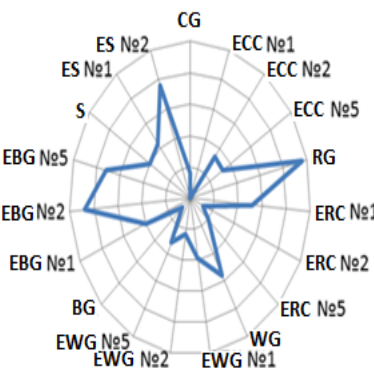

a) $\mathrm{Se}, \mathrm{mg} / 100 \mathrm{~g}$

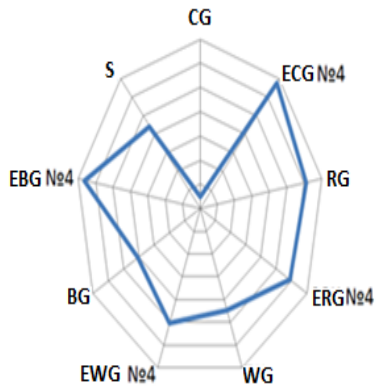

c) Fe, $\mathrm{mg} / 100 \mathrm{~g}$

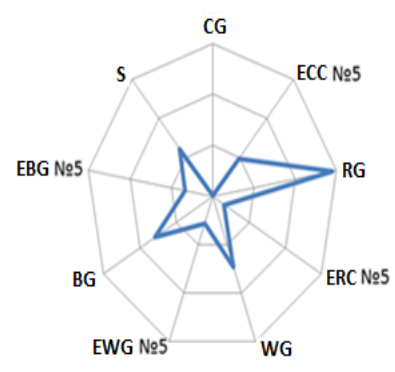

b) $\mathrm{Cr}, \mathrm{mg} / 100 \mathrm{~g}$

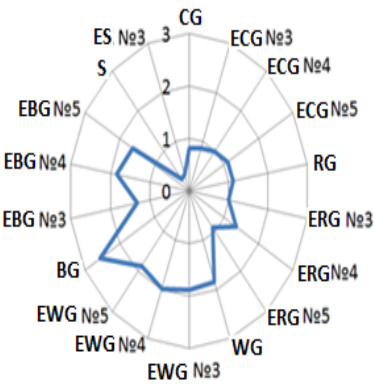

d) $\mathrm{Zn}, \mathrm{g} / 100 \mathrm{~g}$

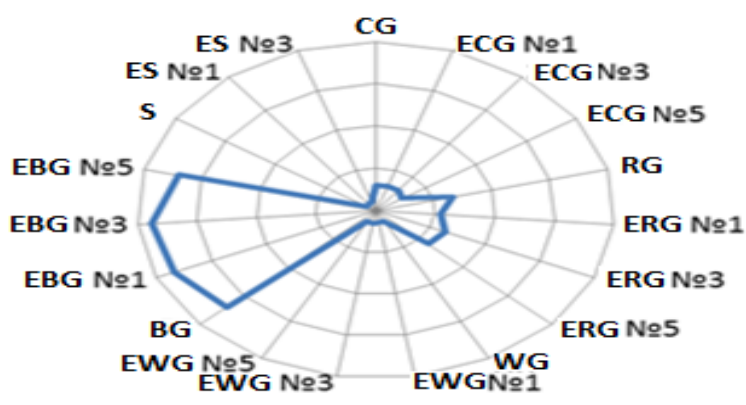

e) $\mathrm{Mg}, \mathrm{mg} / 100 \mathrm{~g}$

Fig. 7: Macro- and Microelement Composition of Extruded Cere-Als Enriched With Carboxylates where No.

Number of the recipe; ECC - extruded corn croup; ERC - extruded rice cereals; EWG - extruded wheat groats; EBG - extruded buckwheat groats; ES - enriched semolina; CG - corn groats (raw materials); RG - rice groats (raw materials); WG - wheat groats (raw materials); BG - buckwheat groats (raw materials); S - semolina (raw materials).

The growth of all micronutrients is observed in all 4 recipes, except for recipe No. 2 which consists of iodine and selenium.

The data show that of all cereals the largest increase in micronutrients according to recipe No. 1 is characterized by buckwheat. So, before enrichment and extrusion, the composition of these micronutrients in aggregate was $67.80022 \mathrm{mg}$., after enrichment and extrusion of cereals, the composition of micronutrients in total was $73.401 \mathrm{mg}$. The gain was $5.60078 \mathrm{mg}$.

Iodine was not found in any of the recipes after the extrusion process, although in the recipe No. 2 in all kinds of cereals it was added in an amount of $55 \mu \mathrm{g} / \mathrm{kg}$, which confirms the scientifically grounded fact that iodine rapidly evaporates under the influence of high temperatures.

In the recipe No. 3 the greatest increase in micronutrients is characterized by buckwheat groats, an increase of $6.01 \mathrm{mg}$, in wheat crop the increase was $0.348 \mathrm{mg}$., in corn groats $0.364 \mathrm{mg}$.

The data show that corn groats characterize the greatest increase in micronutrients, an increase of $0.4893 \mathrm{mg}$. The gain in wheaten groats was $0.185 \mathrm{mg}$., in rice croup $-0,23 \mathrm{mg}$.

In cereals, prepared according to recipe No. 5, the growth of micronutrients was not detected. There is a decrease in their quantity. For example, in buckwheat groats before enrichment and extrusion, the

composition of micronutrients in aggregate was 70,38612 mg., after the introduction of elements and extrusion, the composition decreased to $69.8401 \mathrm{mg}$, which was characteristic for all cereals. Of all the extruded samples, 4 recipes were chosen with the highest growth of micro and macroelements. This: extruded buckwheat groats No. 1; extruded rice cereal No. 5; extruded wheat cereal No. 4; extruded corn croup No. 3. From the selected types of cereals, a pilot batch will be developed in the production shop of "PO Ecos" LLP and additional studies will be carried out.

\section{References}

[1] Report on research work on the topic: "Development of technology for the production of quick-cooking cereals of increased nutritional value with the use of carboxylates" / (interim report 2016 reg. No.10115RK01992) /, Shaimerdenova D.A., Chakanova Zh.M. Abdrakhmanov Kh.A., Sultanova M.Zh., Shaimerdenova P.R., Borovsky A.Yu. - p. 11

[2] Cereal products in the food system of modern man. Shaimerdenova D.A., Chakanova Zh.M. XVIII International Scientific and Practical Conference "Agrarian Science - Agriculture production of Siberia, Kazakhstan, Mongolia and Bulgaria ", April 30, 15.

[3] Diet, nutrition and the prevention of chronic diseases. Report of a Joint WHO/FAO Expert Consultation. Geneva: WHO, 2003. - 149 p. - URL: http://whglibdoc.who.int/trs/ WHOTRS916.pdf/

[4] Batsukova N.L., Filonov V.P., Avetisova A.R. Modern problems of human nutrition. Health and the environment. 2008. № 12. - P. 8-11.

[5] Spirichev V.B., Shatnyuk L.N., Poznyakovski V.M. Enrichment of food products with micronutrients: scientific approaches and practical solutions. Food industry. - 2000. - No. 3.- P. 10-16.

[6] How to solve the problem of mineral deficiency? - URL: http://vitaminclub.in.ua/puti-resheniya-problemy-defitsita-mineralov-v-pitanii/.

[7] Synthesis and study of coordination compounds of copper and zinc carboxylates. - URL: http://refleader.ru/jgejgeotrujgmer.html/.

[8] Sarafanova L.A. Food additives. Encyclopedia, 2nd ed. - SPb: GIORD, 2004.

[9] Gusev A.V. Synthesis of carboxylates of neodymium and polybutadiene with a high content of 1,4-cis units in their presence: the dissertation author's abstract on the competition of a scientific degree of the candidate of chemical sciences. - Voronezh, 2004

[10] Patent of Ukraine to the utility model number 39397. Extracurricular aqueous solution of metal nanocarboxylate / Kosinov M.V. Kaplunenko V.G. / IPC (2006): C07C 51/41, C07F 5/00, C07F 15/00. Published 25.02.2009, bul. №4 / 2009.

[11] Patent of Ukraine to the utility model number 49049. Superficial nanocarboxylate / Kosinov M.V., Kaplunenko V.G. / IPC (2009): C07C 51/41, C07F 5/00, C07F 15/00, C07C 53/00, B82B 3/00. Published Apr 12, 2010, bul. No. 7/20.

[12] Patent of Ukraine to the utility model number 49048. Extracurricular aqueous solution of nanocarboxylate // Kosinov M.V., Kaplunenko V.G. / IPC (2009): C07C 51/41, C07F 5/00, C07F 15/00, C07C 53/00 B82B 3/00. Published Apr 12, 2010, bul. No. 7/20.

[13] Patent US 6,838,095. Ionic silver complex. International Class: A61K 31/19 (20060101); A61K 31/28 (20060101); A61K 47/00 (20060101); A61K 31/185 (20060101). January 4, 2005

[14] US Patent No. 2,644,828, cl. C07C 59/265, publ. 1953.07.07.

[15] Novinyuk L. V. Ammonium-iron citrates are effective sources of bioavailable gel. - Food ingredients, raw materials and additives. 2007. - No. 1. - P. 40. 